\title{
Exploring EFL Writing Teaching Through the Integrated Skills Approach: A Case Study in the Saudi Context
}

\author{
Waad Aljahdali \\ King Abdulaziz University, Jeddah, Saudi Arabia \\ Abdullah Alshakhi \\ King Abdulaziz University, Jeddah, Saudi Arabia
}

\begin{abstract}
This study aims to explore the teaching practices of EFL writing that employ the integrated skills approach. It investigates the benefits and challenges associated with teaching writing that uses the integrated skills approach. The study also aims to provide solutions to the challenges faced by the EFL teachers in teaching writing skills. This study uses a qualitative approach by utilizing two instruments: diary writing of event logs in the first phase, and semi-structured interviews in the second phase. The data were collected in a Saudi university at a Preparatory Year Program (PYP). The sample included four general track teachers. After the analysis of the data, the findings revealed that the integrated skills approach can facilitate students' output; however, students' lower-level of proficiency, a large number of students in writing classes, and time constraints can negatively affect the teaching practices. Suggestive measures were proposed to eliminate the negative aspects that might hinder the implementation of the integrated skills approach while teaching writing skills. Based on the findings, pedagogical implications and directions for future research have been put forward.
\end{abstract}

Index Terms—EFL writing, integrated skills approach, Saudi EFL context, sociocultural theory

\section{INTRODUCTION}

Recently, research has shown an increased interest in communicative language teaching (CLT) to improve students' communicative competence. CLT claims to promote realistic language that is not only used in classrooms but in the real world as well (Oxford, 2001; Hinkel, 2006). Widdowson (1978) was one of the first linguists who encouraged the initiation of integrated skills approach in language teaching as it would facilitate the language learning process and boost learners' proficiency levels. Hinkel (2010) further explains that the emergence of integrated language teaching is often associated with the expansion of CLT.

In language teaching and learning contexts, a prevalent perspective is that people use language skills in tandem, and not separately, in meaningful communications (Hinkel, 2006). In this sense, the integrated skills approach helps learners to use the target language in a natural way, mirroring its use in everyday communication. The aim of the current integrated language teaching models is to promote fluency and accuracy alongside developing learners' socio-cultural communicative competence and enabling them to adapt the target language for different genres and contexts (Hinkel, 2006). In the same vein, the integration of different skills can be reasonably rational to mimic the natural process of skill-mixing and provide ample learning opportunities for students in a classroom environment (Harmer, 2007).

The major innovative trait of CLT in English as a Second Language (ESL) or English as a Foreign Language (EFL) teaching was the integration of the four skills and their various components in one lesson (Hinkel, 2010). For decades, research has suggested CLT to be the most appropriate approach for promoting communicative language learning. However, a debatable question is whether this approach is effective in teaching and learning the writing skill in an EFL environment, as its complex process makes it a challenging phenomenon for teachers and learners.

Writing is one of the most important skills of the English language; however, it constitutes challenges for many EFL learners. These challenges stem from various factors, such as differences in the writing systems of learners' L1 and the English language, inadequate knowledge of English, lack of exposure to L2 writing, inappropriate teaching methodologies, and learners' attitude to EFL writing. These factors directly or indirectly influence the learners' ability to master the writing skills and become proficient writers in the target language. Bearing in mind the deficiencies of traditional teaching methods, practitioners have adopted the CLT approach to teach and help learners develop their writing skills in an interactive way. In the Saudi EFL context, the teaching programs of the universities and schools implement the integrated skills curriculum to allow for communicative language learning inside the classroom. The integrated curriculum takes a holistic view of the learners' skills and teaches writing through the CLT techniques. According to Sanchez (2000), writing skills cannot be learned in isolation. In fact, when learners hear, read, and talk to peers about what they anticipate in a writing task, this can lead to more effective writing skills. 


\section{A. Rationale of the Study}

There is a plethora of studies on EFL writing in the Saudi context that includes different variables, such as reasons behind learners' weak writing skills, error analysis, writing and assessment, and technology-based instruction of writing etc. (e.g., Huwari \& Al-Khasawneh, 2013; Ahamed, 2016; Obeid, 2017; Ezza, Alhuqail, \& Elhussain, 2019). Research on writing instruction based on the integrated skills approach appears to be overlooked in the Saudi EFL context, therefore, there remains an immense need to uncover how writing is taught alongside other language skills and subskills, and whether integrated skills approach fosters or impedes learning in this context.

Despite its prevalence in the Saudi EFL context, there is an urgent need for more research to understand the effects of implementing the integrated skills approach in teaching EFL writing. Therefore, the current research explores the teaching practices of writing in an English language institute that implements the integrated skills approach while teaching receptive skills (reading and listening) and productive skills (speaking and writing) and their sub-skills to foundation year EFL learners. The current study is important in relation to the achievement levels in English classes which are lower than expected, despite the integrated textbooks that are being used in the Saudi EFL context (Khan, 2011).

For L2 learners, writing in a target language is often a daunting task. Harmer (2007) believes that some students are hesitant writers due to several reasons; perhaps they have written little in their first language (L1) or cannot find or come up with thoughts on a topic. However, it is the teacher's job to help hesitant students build the "writing habit" in order for them to approach writing tasks with enthusiasm. He further suggests certain ways to do this, one of which is to ensure that teachers give students enough information to do the tasks, and make sure that they have a sufficient amount of the right type of language to do the writing tasks. In relation to the integrated skills approach, providing students with the right type of language might be one of its most notable elements where students are provided with a comprehensible input through a range of different skills. Moreover, scholars such as Hinkel (2018), Sanchez (2000), Oxford (2001), and $\mathrm{Su}$ (2007) underscore the beneficial role of the integrated skills approach that can eventually improve students' learning. Therefore, it is essential to understand how this approach is considered by EFL teachers while teaching writing skills in the Saudi EFL context.

On the other hand, the integrated skills approach can have some challenges related to time while considering other skills at the same time (Mezirgue, 2016). Hence, the identification of challenges related to teaching EFL writing with the integrated skills approach may help teachers minimize their impact by adopting teaching approaches that can help learners overcome their writing difficulties. In addition, suggested pedagogical implications might help in decreasing the effects of the factors that lead to such challenges.

\section{B. Theoretical Underpinnings}

The sociocultural theory is most relevant to this research as it goes hand in hand with the aims of this research, which are to provide insights into the benefits and challenges of teaching EFL writing while employing the integrated skills approach, and to suggest pedagogical implications that facilitate the teaching and learning of writing based on the notions of the sociocultural theory; scaffolding and Zone of Proximal Development (ZPD). Recent theoretical developments have revealed that the sociocultural theory through some of its predominate notions, such as the ZPD and scaffolding play a pivotal role in enhancing pedagogical practices, especially in writing lessons. Today, sociocultural theory constitutes the major paradigm of research on writing (MacArthur, Graham, \& Fitzgerald, 2008).

\section{Research Questions}

This paper aims to identify the benefits and challenges of teaching EFL writing through the integrated skills approach and suggest solutions to problems that might arise in writing lessons. It also aims to outline pedagogical implications for EFL teachers, policymakers, and EFL students based on the implementation of an integrated skills language curriculum. This study is guided by the following two overarching research questions:

1. What are the benefits and challenges of teaching EFL writing through the integrated skills approach?

2. How do EFL teachers overcome the challenges of teaching writing skills while using the integrated skills approach in EFL writing classrooms in the Saudi context?

\section{LITERATURE REVIEW}

The integration of skills offers many learning opportunities for students in the classroom (Harmer, 2007). Further, empirical findings in the Saudi EFL context proved the effectiveness of integrated skills teaching. For example, Mekheimer (2011) conducted a quasi-experimental study on EFL undergraduate students as teachers were not using the assigned books to their full potential, which were meant for skills integration, the researcher realized that the teachers neglected many integrated activities. As they were mainly concerned with completing all the units while leaving important activities, there was little consideration for skills integration. The study investigated the integrated holistic method for teaching English skills in a Saudi university. The findings of the study confirmed the effective role of integrated skills teaching by teaching the four language skills in an integrative manner. The difference between the experimental group and the control group was the emphasis on skills integration. The experimental group emphasized integrating all four language skills, whereas the control group did not emphasize skills integration. In the second phase 
of the research, the participating teachers were involved through questionnaires, diaries, and interviews. It was also found that students' performance was improved in writing through the integration of all other skills. Ultimately, the results imply that the segregated approach may not help develop students' competence in English as the experimental group writing performance was developed more notably than the students of the control group as they did not stress skills integration.

As for Al-Dosari (2016), his study investigated the influence of integrated reading and writing on learners' writing ability. The researcher used a quasi-experimental design composed of experimental and control groups. The experimental group performance was positive in writing and reading comprehension altogether which was a result of the emphasis of integrating writing skills with other skills and sub-skills of reading and writing. Al-Dosari (2016) deduced that the quality of students' writing was positively influenced when it was integrated with reading skills. This suggests that using the integrated skills approach in language classes helps in developing learners' language skills, and especially promoting writing skills. Consequently, these results confirm the necessity of integrating reading and writing skills.

Despite the positive results of Mekheimer's (2011) and Al-Dosari's (2016) studies, it is important to note that the sample of the studies were students at the college of languages and translation, which implies their higher level of English than those enrolled in the Preparatory Year Program (PYP). Hence, these results may not be generalizable to the PYP students. Since these studies were conducted at the same university, there is a need for more studies in different Saudi universities with varied levels of EFL students.

\section{A. Integrated Skills Approach}

The integrated skills approach is a mode of instruction that is concerned with the teaching of the four main language skills (reading, listening, speaking, and writing) and their sub-skills. Hinkel (2010) notes that this approach emerged from communicative language approaches as a reaction to more traditional approaches in the field of ELT.

It is important to define some of the main terms used in this study. Oxford (2001) portrayed English language teaching as a tapestry and stated that: "the tapestry is woven from many strands, such as the characteristics of the teacher, the learner, the setting, and the relevant languages (i.e., English and the native languages of the learners and the teacher)" (pp.1-2). Oxford (2001) added:

In addition to the four strands mentioned above--teacher, learner, setting, and relevant languages-other important strands exist in the tapestry. In a practical sense, one of the most crucial of these strands consists of the four primary skills of listening, reading, speaking, and writing. This strand also includes associated or related skills such as knowledge of vocabulary, spelling, pronunciation, syntax, meaning, and usage. The skill strand of the tapestry leads to optimal ESL/EFL communication when the skills are interwoven during instruction. This is known as the integrated skill approach. (Oxford, 2001, pp. 1-2)

Widdowson (1978) is one of the earliest linguists who called for initiating the integrated skills teaching to further language learning and improve learners' proficiency. He pointed out that language learning does not occur in separated units, although language skills can be easily taught separately. In the natural learning context of L1, we learn all the skills and not only one language skill at a time. Likewise, Oxford (2001) indicated that the traditional ESL/EFL programs implement the segregated skills approach, and this teaching system goes against the natural process of L1 acquisition. However, Peregoy and Boyle (2001) stated that in L1 acquisition, oral language development occurs fully and earlier than written language development. Accordingly, Widdowson's (1978) and Oxford's (2001) expositions imply that even L2 skills are not learned in isolation. Not only that, but segregated skills teaching might be unsuccessful in preparing students for job-related, academic-related or everyday life communication, although it is possible to teach skills separately in the classroom (Oxford, 2001). The use of integrated skills teaching can be found in different models. Content-based and task-based instructions are two popular types of integrated skills approaches used in ESL/EFL classrooms (Oxford, 2001).

\section{B. The Benefits and Challenges of the Integrated Skills Approach}

Several empirical studies have investigated the notion of integrated skills teaching in different contexts. For example, $\mathrm{Su}$ (2007) investigated the impact of a teaching practice using the integrated skills approach in comparison to a teaching practice using the segregated skills approach in a higher education setting in Taiwan. Her study measured students' satisfaction of integrated skills teaching and to see, if over the course of the study, students changed their views regarding the segregated skills teaching. The findings of the study were in favour of the integrated skills teaching as most of the participants indicated that this approach provided them with many opportunities for in-class authentic communication while only a few of the participants thought that language skills should be taught separately. Moreover, one of the benefits of the integrated skills approach is that it gives learners an actual picture of the "richness" of the English language when it is used in communication (Oxford, 2001), and the integrated skills approach was identified as a motivating factor in language learning (Oxford, 2001; $\mathrm{Su}, 2007$ ).

On the contrary, Kebede (2013) identified three factors that could hinder integrated skills teaching: a) school-related factors, b) teachers'-related factors and c) learners'-related factors. Factors related to school are concerning policy, equipment, and environment of the institution. Furthermore, competence and belief were identified as factors related to teachers. Similarly, Richards (2001) indicated that teachers might think it is impossible to teach more than one skill at a 
time or that it is easier and "logistically simpler" to teach language skills separately than to teach them all together at a time. This implies that teachers' beliefs are an important factor for the success of an educational process. As for the last factor, it was identified as relating to students' language proficiency, attitudes, and motivation. Kebede (2013) pointed out that those with poor language proficiency including limited grammar and vocabulary knowledge, basic language knowledge, and lack of motivation might impede integrated skills teaching and vice-versa. In the same vein, Alseghayer (2011) noted that students' beliefs, attitudes, and perceptions in ESL/EFL classrooms contribute greatly to the process of English language learning and their success. Thus, students' attitudes play an immense role in their learning endeavours. Even if the teaching system was appropriate, it seems that without motivation and a positive attitude, learners may not make any progress in their bid to learn the English language.

The integrated skills approach might enhance students' communicative competence; however, its enactment may not accomplish similar proficiency rates across all four skills (Hinkel, 2018). Furthermore, the problem of large classes is likely to affect its implementation as highlighted by Hinkel (2010) that integrated skills teaching might not be a practical choice in areas where teachers teach large classes. As for teachers' abilities, integrated language skills curricula require flexible and well-trained teachers. According to Hinkel (2010) in many cases, instructors should be familiar with discourse based instructional models. Moreover, the complexity of integrated language teaching may appear when the teaching materials have to account for learners of mixed abilities (Hinkel, 2010).

Despite these obstacles, Hinkel (2018) suggested that for the teaching-learning process to be successful in any EFL/ESL context and at any level, the enactment of integrated skills approach is fundamental. Since the integrated skills teaching might be demanding, Hinkel (2018) suggested a solution that may help in saving time when teaching through this approach:

When teaching integrated L2 skills in general, and speaking skills in particular, pre-teaching the needed vocabulary and grammar constructions and providing examples can often help learners manage the demands generated by the process of learning to improve multiple L2 skills. (Hinkel, 2018, p. 4)

Although Hinkel's (2018) study is about the speaking skills, there is a clear indication of all four language skills, including writing. Writing and speaking are related to each other as they are both productive skills, therefore, teachers may consider pre-teaching certain parts of the topic before the writing lesson as a means of managing the class time effectively.

Linking the teaching of writing to other language skills, such as reading, listening, and speaking might eventually help learners use the language in a communicative way. For instance, linking reading and writing may create opportunities for listening and speaking at the same time. Sanchez (2000) considers writing practice closely connected to all other language skills, reading, listening and speaking. Nevertheless, it is important to bear in mind that not all learners will achieve high level of proficiency in writing, as L1 interference may result in producing unacceptable forms. Sanchez (2000) further explained that if there is a constant skill integration practice, more efficient outcomes will be achieved in writing exercises.

Writing teachers may encounter various pedagogical challenges in the classroom. According to Mezrigui (2016), some teachers often complain about the shortage of time when teaching with the integrated skills approach. In his context, grade six students' sessions are only an hour long, due to which, teachers do not have enough time to complete all the activities. Hence, some tasks are assigned as homework or left behind. Hinkel (2010) also pointed out that the integrated skills teaching might be demanding for both instructors and learners. Moreover, Mezrigui (2016) attributed one of the possible impediments of integrating skills to weak/slow learners. Leki (2001) pointed out that correcting grammar exercise and giving feedback to students in large classes is considered a time-consuming task. Similarly, Akram and Malik (2010) pointed out that large classes or limited time of teaching might negatively affect the successful implementation of integrated skills teaching. However, they indicated that teachers' experiences can help them manage such issues.

\section{Teaching Writing through the Integrated Skills Approach and its Relation to Communicative Language Teaching $(C L T)$}

Communicative language teaching (CLT) is a common teaching strategy used in many language schools nowadays. Unlike the traditional approaches to language learning, CLT aims to provide learners with real-life communication opportunities. According to Richards and Rodgers (2001), the roots of CLT go back to the reforms in the British language teaching tradition dated to the late 1960s when British applied linguists envisioned the importance of communicative competence in comparison to the mastery of structures. Since the mid-1970s, CLT expanded in scope as American and British proponents considered it as an "approach" and not a "method" that aims to: "a) make communicative competence the goal of language teaching, b) develop procedures for the teaching of the four language skills that acknowledge the interdependence of language communication" (Richards \& Rodgers, 2001, p.155). It is the "comprehensiveness" of CLT that made it stand out (Richards \& Rodgers, 2001).

CLT emphasizes the use of language in a communicative manner, and this goes in line with the integrated skills approach. Hinkel (2010) explained that the main feature of CLT-based ESL or EFL teaching is the integration of macro skills with their components. In support of this view, Richards and Schmidt (2002) confirmed that the four macro language skills are utilized for effective communication in L2. This communication is effective due to a close connection between oral and written language skills. According to Peregoy and Boyle (2001), in everyday 
communication, language uses of written and spoken language usually occur together, not separately from one another. Hence, using written and spoken language adopts one of the primary principles of CLT and allows students to use all language skills in a communicative way.

As there seems to be no study that has considered teaching EFL writing with the integrated skills approach using qualitative methods, this qualitative study will bridge that gap and contribute to the body of knowledge. To resolve the problems of EFL writing that teachers and learners encounter, it is important to explore the nature of teaching practices, especially related to the integrated skills teaching that always considers several skills alongside the writing. Thus, this article investigates the nature of a teaching system in a language institute that implements the integrated skills approach with a focus on teaching EFL writing. The study also considers the effects of the teaching process and uncovers its benefits and challenges in the Saudi EFL context.

\section{METHODOLOGY}

\section{A. Research Paradigm}

This study is underpinned by the interpretivist paradigm. Unlike the positivist approach, interpretivism focuses on indepth variables (Alharahsheh \& Pius, 2020). Interpretivism is a methodological philosophy that has come to challenge quantitative methods in social science research and the positivist paradigm during the mid-twentieth century. In humanities and social sciences, the impact of interpretivism on qualitative research is evident (Hammersley, 2013). Furthermore, interpretivist researchers consider the inside meaning or perspective from the part of the research participants as valuable social knowledge (Wahyuni, 2012). One of the requirements of the interpretivist paradigm is adopting an exploratory orientation requiring the researchers to understand the distinctive perspective of the people involved and to monitor how their actions are revealed in a specific context. It is meant to find out the rationale of what might look at first odd, evil, or irrational; thus, it requires a comprehensive exploration of the experiences and perspectives of people (Hammersley, 2013).

\section{B. Research Design}

Qualitative methods offer an effective way of understanding certain phenomena; therefore, the current study employs a case study research design to gain a detailed understanding of the studied phenomenon. According to Dörnyei (2007), 'the rich data obtained about the participants' experience can widen the scope of our understanding and can add datadriven (rather than speculative) depth to the analysis of a phenomenon" (p. 40)

\section{Context of the Study}

The context of this study is an English language institute of a Saudi Arabian university. As the study was conducted in an EFL context, the complexity of teaching the English language and writing skills might be evident. This English language course is taught to PYP students who use textbooks that encompass all language skills, i.e., listening, speaking, reading, and writing, and their sub-skills (grammar, vocabulary, spelling, pronunciation, etc.). Hence, writing lessons are delivered through the integrated skills approach.

\section{Participants}

For the purpose of data collection, four EFL teachers were recruited from a Saudi university following a snowball sampling procedure, where the participating teachers were recruited according to their availability. However, they were selected by the level they were teaching. The rationale behind choosing level 102 and level 103 teachers only is because more sophisticated writing tasks are taught in these courses in comparison to level 101 courses.

\section{E. Research Instruments}

Data were collected from multiple sources, utilizing teachers' diary forms about their experiences in teaching EFL writing, and phone interviews. Overall, as there were four participants, eight diary forms were received and four interview protocols were prepared.

1. Diary Writing

Since the 1980s, diary studies have been used by learners in applied linguistics to gain personal accounts of language learning and by parents to document their children's progress of L2 development (mainly bilingual children). Diary studies have also been used in teacher education programs. Diary study is defined as "an insider account" in which participants are considered co-researchers (Dörnyei, 2007, p. 157). They are based on a self-report from participants, which diminishes the inaccuracy that might result from not remembering things accurately (van Eerde, Holman, \& Totterdell, 2005). Research diaries range from highly structured event logs to unstructured narrative accounts (Sheble $\&$ Wildemuth, 2009). The type of diary used in this research is an event-contingent diary. Event-contingent studies require participants to provide a self-report each time a specific event occurs (Dörnyei, 2007). In this case, teachers were asked to write about how they taught two writing lessons.

2. Semi-structured Interviews

To obtain further in-depth information on teaching writing, interviews were chosen as a follow-up instrument, which in qualitative inquiries is the most adopted method (Dörnyei, 2007). In an ordinary semi-structured interview, the 
interviewer prepares questions or topics to be covered in the interview session. However, when and how to ask questions can be flexible, and there is flexibility for the interviewees to answer according to the questions (Edwards \& Holland, 2013). This study has used semi-structured interviews. Due to the general condition of online learning during the academic year 2020, interviews were conducted over the phone.

\section{F. Data Analysis}

To analyze the qualitative data, content analysis technique was initially used which was followed by thematic analysis. The analysis was manually performed using Microsoft word.

\section{RESULTS}

The results of the study generated different views regarding the benefits and obstacles of teaching writing through the integrated skills approach, the challenges were followed by teachers' solutions to deal with some of the encountered challenges. Figure 1 shows the emerging themes.

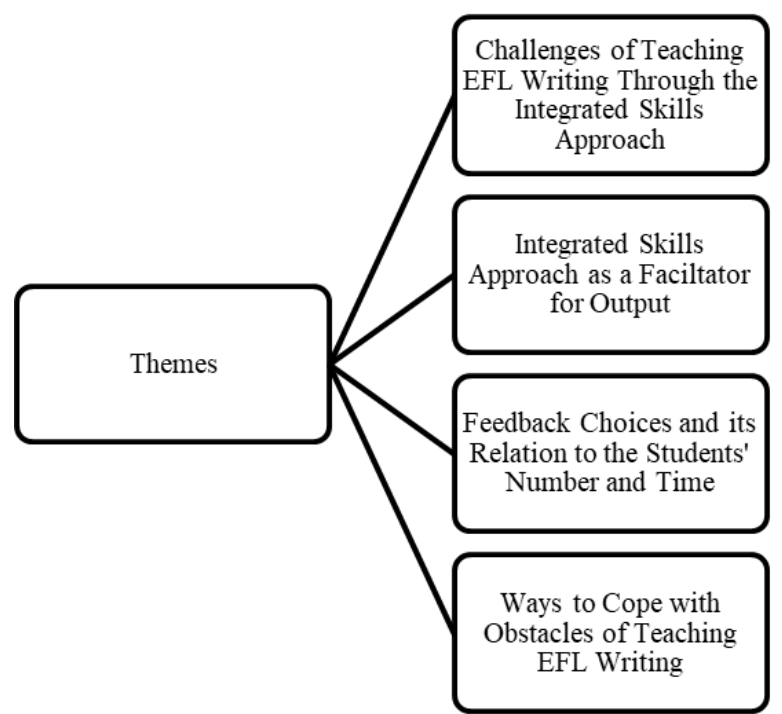

Figure 1. Emerging themes

A. Challenges of Teaching EFL Writing through the Integrated Skills Approach

This theme includes some of the challenges the participants encounter when teaching writing through the integrated skills approach. Maram outlined different challenges when teaching EFL writing in her class:

Time, first of all, time. And the students will be confused if you gather all the skills and practice them with writing. They will be, you know, confused, so you should tell them that this is listening skill and then we will produce writing; you specify the skill itself. We are now learning listening, and then we will learn writing. (Maram)

Maram also emphasized the students' reception of knowledge in an EFL class:

If you give them more than one skill, you will not be successful. They have, you know, reception for the skills, it is maybe 10 to 15 minutes they will concentrate with you, and then they will get bored. So, you cannot practice all the skills to produce writing. (Maram)

Maram also believes that this approach might be confusing to the students:

So, the students would be a bit confused and worry about the time because all of them want to be corrected. And their writing, they want it to be read and displayed in the class. (Maram)

However, to Marlene, it is the level of the students' proficiency that seems to constitute the challenge as she explained:

Usually, the obstacle is coming from the students themselves. Like I said, they might not have the imagination; the critical thinking skills to be able to come-up with reasons and examples. Their vocabulary is limited. They learn the vocabulary for the sake of passing exams; they are not learning it to use it. So, yeah, that is one of the obstacles. It is comfortable to them, so they will reverse back to basic language instead of using new vocabulary that they learned. And when it comes to writing, as well, some tend to write as they speak, or Google translate it in their head, so it comes out in the wrong word order. And yeah, that is the biggest problem I have; lack of vocabulary. (Marlene) 
In support of this view, Ahlam draws on students' proficiency level: "if they do not have the basic things like grammar and they do not know how to write sentence with a good structure, it takes time. So, yes, it depends on the students' level sometimes". (Ahlam)

\section{B. Integrated Skills Approach as a Facilatator for Output}

This emerging theme indicates how teaching writing through the integrated skills approach has an effective role when it comes to the output stage in the language classroom. Marlene indicated the following:

Well, it helps the students to be able to improve their writing because they have the vocabulary, they have the grammar. If they want to improve their writing, then they are more focused on the grammar, checking that the grammar is correct, and are encouraged to use the vocabulary to make their writing better because they are expected to. So, yeah, it is something for them to fall back on. (Marlene)

In the same vein, Ahlam shared the same view: "to have input from using other skills to help them to write to product something". (Ahlam)

Similarly, Amany commented on the presentation of knowledge needed for the output stage:

It makes it easier for them; you know. So, they feel more comfortable there is nothing new about what you are going to write, we already know what we are supposed to write; the vocabulary, everything is there. (Amany) On the other hand, if it was not integrated, so they are blank. They have no idea to write about, and it would be a bit difficult for me to mention topics from scratch but, this way, they already have an idea they have covered some points in the introduction, in the reading, in the grammar, so, that way it actually helps me. (Amany)

\section{Feedback Choices and its Relation to the Students' Number and Time}

When Ahlam was asked about the number of students in her class, she identified as 40 students. She indicated that: "yes, it is a big number. I think the challenge is when I give them feedback. I cannot give the feedback to each student, so in this case, usually, I gather the most important mistakes and I correct them, or we correct them together on the board". (Ahlam)

In the same vein, Amany also drew on giving individual attention and how the large number of students' makes it difficult for teachers to give detailed feedback to each student during the class time. "if I have large number of students, it gets difficult to give individual attention". (Amany)

Amany further elaborated the notion of individual attention:

You know, there are individual differences between the students, they are not at the same level normally, or they do not understand the points right away. Some students need more time, more attention, and that gets difficult for me as a teacher. They have large number of students in the classroom, so, I cannot really give individual attention to each one of them. (Amany)

\section{Ways to Cope with Obstacles of Teaching EFL Writing}

This final theme draws on some solutions the participants of this study indicated which can help teachers overcome challenges they encounter in their writing class. Amany believes that an email can help when it comes to not being able to check on the students' drafts:

I ask them to send their writings by email or you know come and see me in my office hours. Like now, we are doing the online classes but if I'm in class, then I would ask them to come in my office hours and I check their writing so I can cover as much as I can. (Amany)

A similar view is indicated by Ahlam:

As I told you before, I may take their writing with me or maybe some of them those who finish and we comment on their writing and I take the others' papers to correct them at home and the most important mistakes I found, I discuss them with the students. (Ahlam)

On the other hand, Ahlam gives lower-level students more attention to facilitate the writing process for them. "I give them more attention by explaining more to them, maybe sometimes using L1. And sometimes, I show them the vocabulary or the form of the sentence". (Ahlam)

\section{DiscUSSION}

This section discusses the results of the research questions in a sequential order.

Q1: What are the benefits and challenges of teaching EFL writing through the integrated skills approach?

This question generated different views on the implementation of the integrated skills approach when teaching writing in the Saudi EFL context. Some of the findings suggest that the integrated skills curriculum offers many avenues for input; however, it may also be considered a time-consuming practice that leads to the learners' confusion.

\section{A. Benefits}

There was a general agreement that teaching writing through the integrated skills approach helps in the output stage of a writing lesson. The results indicated that this approach with its different skills and sub-skills provides students with a comprehensible input to help them in the writing tasks that lead to their improved learning outcomes. This is in line with what Sanchez (2000) found that constant integration of skills yielded more effective results in writing exercises. 
This is demonstrated by the contribution of other skills, such as reading texts, providing structure, and introducing new vocabulary, which are meant to facilitate students' writing. The efficiency of the integrated skills approach is reflected on by this teacher: "It makes it easier for them; you know. So, they feel more comfortable there is nothing new about what you are going to write, we already know what we are supposed to write; the vocabulary, everything is there." (Amany)

By comparing the current findings with Al-Dosari's (2016) study, his results proved that when integrating reading and writing skills, students writing were greatly improved. This suggests the significant role of skills integration in fostering students' writing skills in an EFL setting. Although the integrated skills approach provides students with a comprehensible input, the current study indicates that some students might experience difficulties in writing, mainly because of their lower proficiency levels. This result might be attributed to the fact that Al-Dosari (2016) considered EFL students enrolled in the English language department; unlike the students who are taking compulsory English courses in the PYP. Hence, they might lack the motivation to learn English.

\section{B. Challenges}

This study illustrates that the integrated skills approach can be time-consuming and confusing for the EFL learners. This finding is consistent with that of Mezrigui's (2016) where he noted that some teachers complained about the shortage of time while using the integrated skills approach in teaching. Although Mezrigui's (2016) context is different to the current context in terms of age groups, the issue remains the same despite the learners' age. Furthermore, it is worth noting that describing the integrated skills approach to be confusing for students, might be related to what Richards (2001) pointed out that teachers might deem it impossible to teach more than one skill at a time or that it is easier to teach language skills separately. Thus, if we consider the time factor and students level in relation to skills integration, a possible reason for experiencing difficulties with it might be associated with learners' needs, such as wanting to be corrected or it might also be related to their proficiency level, as indicated by some of the participants.

One interesting finding is that students have a limited reception capacity for absorbing information during the class. A possible explanation for this to occur during the class time might be attributed to the long hours of teaching in the language classroom. Another possible reason for losing interest or having limited reception of information could be related to the teaching methods, and the environment of the classroom. This is pointed out by one of the participants:

If you give them more than one skill, you will not be successful. They have, you know, reception for the skills it is maybe 10 to 15 minutes they will concentrate with you, and then they will get bored. So, you cannot practice all the skills to produce writing. (Maram)

Among the challenges, large classes and time limitations were highlighted by the participants. In the same way, Hinkel (2010) noted that integrated skills teaching might not be practical in areas where teachers have to teach large classes. Similarly, Akram and Malik (2010) pointed out that an integrated skills approach helps in making the lessons dynamic if applied successfully. However, large classes or limited time of teaching might negatively affect the successful implementation of integrated skills teaching as indicated by the findings of this study: "So, the students would be a bit confused and worry about the time because all of them want to be corrected. And their writing, they want it to be read and displayed in the class. " (Maram)

This could be due to the fact that usually large classes affect teaching in terms of guiding students individually and trying to respond to their different needs, as evidently stated in the current study. The challenge might be more apparent especially in the case of lower-level students when teachers find it difficult to respond to individual differences or individual mistakes in large classes while considering other sets of skills during class time. However, by minimizing students' number and increasing the allotted time to teaching writing, the problem can be easily solved.

Q2: How do EFL teachers overcome the challenges of teaching writing skills while using the integrated skills approach in EFL writing classrooms in the Saudi context?

The last research question finds solutions to the problems highlighted by the EFL teachers in this study. The results include the use of emails as a medium for correction, the use of L1 for explanation, and the manifestation of examples for lower-level students.

\section{Solutions}

The findings suggest solutions to the challenges identified by the participants of this study. As indicated earlier, time appears to affect the teaching of writing skills, especially at the feedback and correction stage. This is similar to what Leki (2001) established that correcting grammatical errors and providing students with feedback in large classes is a challenging and time-consuming task. Due to the large number of students, it was pointed out that some students send their drafts via email for correction. Although it seems to be a good practice, some students might seek help of others in writing their drafts, and that might not reflect their actual level of writing. However, considering the challenging phenomenon of large classes, it might be the only solution. Similarly, Mekheimer (2011) pointed out that teachers should be trained to manage time effectively as the integrated skills approach requires more time than teaching with a segregated skills approach. Therefore, it is time-consuming in comparison to the segregated skills approach.

As for the students' proficiency levels, it was found that the use of students' L1 can help them, especially the weaker ones. Moreover, displaying the form or vocabulary might help them to start the writing task with more confidence. Indeed, this kind of assistance mirrors scaffolding since presenting examples to students is one way of assisted learning. 
Further, this participant clarified the way she manages this issue: "I give them more attention by explaining more to them, maybe sometimes using L1. And sometimes, I show them the vocabulary or the form of the sentence." (Ahlam)

\section{CONCLUSION}

Overall, the findings highlight the importance and efficiency of teaching EFL writing with the integrated skills approach to provide learners with a comprehensible input; however, the students' proficiency level and their inadequate vocabulary can influence the application of this approach effectively in an EFL classroom. It is also illustrated that the large number of students and time constraints negatively affect the teaching of EFL writing. Therefore, the educational institutions might consider extending the time allotted for teaching writing skills and reduce the number of the students in language classrooms. This result is in line with previous studies wherein large classes and time limitations were identified as two factors affecting teaching practices that use the integrated skills approach. Furthermore, the findings contribute to the understanding of the benefits and possible challenges that might arise in an EFL environment.

\section{RECOMMENDATION FOR FUTURE RESEARCH}

More research is required to understand the teaching of writing skills and the process of EFL writing, with the integrated skills approach. This is an important issue for future research since the integrated skills approach is commonly used in the Saudi context. Moreover, future research can explore the factors that might improve or obscure teaching and learning of EFL writing while using the integrated skills approach. Also, it will be interesting to conduct a study comparing two different teaching systems, such as a semester-based teaching and a modular system to assess their outcomes and examine their impact on the integrated skills approach in the Saudi EFL context.

\section{PedigogicAl IMPLiCATIONS}

The findings of the current study have certain pedagogical implications for EFL teachers, policymakers, and students:

- For EFL teachers: Pre-teaching vocabulary might help in saving time as suggested by previous studies in the field of SLA.

- $\quad$ For policymakers: Reducing students' number might have more fruitful results for teachers and students alike.

- For students: Practicing the newly taught vocabulary in context might help them internalize the new words and use them in the writing tasks.

\section{REFERENCES}

[1] Ahamed, Y. E. F. (2016). An investigation of writing errors of Saudi EFL university students. International Journal of Social Science and Humanities Research, 4(2), 189-211.

[2] Akram, A., \& Malik, A. (2010). Integration of language learning skills in second language acquisition. International Journal of Arts and Sciences, 3(14), 231-240.

[3] Al-Dosari, H. (2016). Effects of an integrated reading/writing approach on improving writing skills of EFL student Dirasat: Educational Sciences, 43, 761-771

[4] Alharahsheh, H., \& Pius, A. (2020). A review of key paradigms: Positivism vs interpretivism. Global Academic Journal of Humanities and Social Sciences, 2(3), 39-43.

[5] Alseghayer, K. (2011). Scatter views about English language learning and teaching. Riyadh, Saudi Arabia: Hala print Co.

[6] Dörnyei, Z. (2007). Research methods in applied linguistics: Quantitative, qualitative, and mixed methodologies. Oxford: Oxford University Press.

[7] Edwards, R., \& Holland, J. (2013). What is qualitative interviewing? USA: A \& C Black.

[8] Ezza, E., Alhuqail, E., \& Elhussain, S. (2019). Technology-based instructional intervention into an EFL writing classroom. Cypriot Journal of Educational Sciences, 14(4), 507-519. https://doi.org/10.18844/cjes.v11i4.3904.

[9] Hammersley, M. (2013). What is qualitative research? London, UK: Bloomsbury.

[10] Harmer, J. (2007). The practice of English language teaching (4th Ed.). England: Pearson Longman.

[11] Hinkel, E. (2006). Current perspectives on teaching the four skills. TESOL Quarterly, 40(1), 109-131. https://doi.org/10.2307/40264513.

[12] Hinkel, E. (2010). Integrating the four skills: Current and historical perspectives. Oxford Handbooks Online. https://doi.org/10.1093/oxfordhb/9780195384253.013.0008.

[13] Hinkel, E. (2018). Teaching speaking in integrated-skills classes. The TESOL encyclopaedia of English language teaching.

[14] Huwari, I. F., \& Al-Khasawneh, F. M. (2013). The reasons behind the weaknesses of writing in English among pre-year students at Taibah University. English for Specific Purposes World, 14(38), 1-9.

[15] Kebede, D. (2013). The implementation of language skills integration In English as a foreign language (EFL) classes: Jimma college of teachers' education in focus (Doctoral dissertation, Jimma University). OpenDocs Repository. https://opendocs.ids.ac.uk/opendocs/handle/20.500.12413/6973.

[16] Khan, I. A. (2011). Learning difficulties in English: Diagnosis and pedagogy in Saudi Arabia. Educational Research, 2(7), 1248-1257.

[17] Leki, I. (2001). Material, educational, and ideological challenges of teaching EFL writing at the turn of the century. International Journal of English Studies, 1(2), 197-209.

[18] MacArthur, C. A., Graham, S., \& Fitzgerald, J. (2008). Handbook of writing research. USA: Guilford Press. 
[19] Mekheimer, M. (2011). Effectiveness of an integrated, holistic pedagogy of EFL skills in college students. The Educational Research Journal, 25(100), 41-74.Mezrigui, Y. (2016). Impediments to integrating language skills in young learners' EFL classes: Whys and a way out via mini-sagas. International Journal of English Language Teaching, 4(5), 1-15.

[20] Mezrigui, Y. (2016). Impediments to integrating language skills in young learners' EFL classes: Whys and a way out via minisagas. International Journal of English Language Teaching, 4(5), 1-15.

[21] Obeid, R. (2017). Second language writing and assessment: Voices from within the Saudi EFL context. English Language Teaching, 10(6), 174-181. https://doi.org/10.5539/elt.v10n6p174.

[22] Oxford, R. (2001). Integrated Skills in the ESL/EFL Classroom. ERIC Digest.

[23] Peregoy, S., \& Boyle, O. F. (2001). Reading, writing, \& learning in ESL. New York, NY: Longman.

[24] Richards, J. C. (2001). Curriculum development in language teaching. Cambridge, UK: Ernst Klett Sprachen.

[25] Richards, J. C., \& Rodgers, T. S. (2001). Approaches and methods in language teaching. UK: Cambridge University.

[26] Richards, J. C., \& Schmidt, R. (2002). Longman dictionary of applied linguistics and language teaching. Harlow, UK: Longman.

[27] Sánchez, M. Á. A. (2000). An approach to the integration of skills. Didáctica. Lengua y literatura, 2000 (12), 21-41.

[28] Sheble, L., \& Wildemuth, B. (2009). Research diaries. In B. Wildemuth (Ed.), Applications of social research methods to questions in information and library science (pp. 211-221). Santa Barbara, CA: Libraries Unlimited.

[29] Su, Y. (2007). Students' changing views and the integrated-skills approach in Taiwan's EFL College classes. Asia Pacific Education Review, 8(1), 27-40. https://doi.org/10.1007/bf03025831.

[30] van Eerde, W., Holman, D., \& Totterdell, P. (2005). Diary studies in work psychology [Editorial Special Section]. Journal of Occupational and Organizational Psychology, 78(2), 151-154. doi: 10.1348/096317905X40826.

[31] Wahyuni, D. (2012). The research design maze: Understanding paradigms, cases, methods and methodologies. Journal of applied management accounting research, 10(1), 69-80.

[32] Widdowson, H. G. (1978). Teaching language as communication. UK: Oxford University Press.

Waad A. Aljahdali holds a Bachelor's degree in the English language from King Abdulaziz University, Jeddah, Saudi Arabia. She is currently pursuing a Master's degree in TESOL at King Abdulaziz University, Jeddah, Saudi Arabia. She has a teaching experience of two years in the English language to EFL learners. Her research interests revolve around teaching and learning the productive skills of the English language.

Abdullah Alshakhi is an Associate Professor of Applied Linguistics and the Head of Curriculum and Testing Unit at the English Language Institute at King Abdulaziz University. With particular research interests in language testing and assessment literacy, construct validity, writing assessment, and language policy, Dr. Alshakhi has been published in both local and international journals. $\mathrm{He}$ is actively involved in several workshops involving language assessment and testing through the Educational Testing Service (ETS), Cambridge Assessment as well as the European Association of Language Assessment and Testing (EALTA). 